\title{
System Dynamics Modelling of Remanufacturing and Recycling Mode Based on Closed-Loop Across-Chain Competition
}

\author{
Shidi Miao, ${ }^{1,2}$ Deyun Chen, ${ }^{1,2}$ and Tengfei Wang ${ }^{2}$ \\ ${ }^{1}$ Computer Science and Technology Postdoctoral Programme, Harbin University of Science and Technology, Harbin 150080, China \\ ${ }^{2}$ School of Computer Science and Technology, Harbin University of Science and Technology, Harbin 150080, China \\ Correspondence should be addressed to Shidi Miao; msdking@126.com
}

Received 19 April 2017; Revised 21 June 2017; Accepted 22 June 2017; Published 21 August 2017

Academic Editor: Gabriella Bretti

Copyright (c) 2017 Shidi Miao et al. This is an open access article distributed under the Creative Commons Attribution License, which permits unrestricted use, distribution, and reproduction in any medium, provided the original work is properly cited.

\begin{abstract}
To face the reality of resources exhaustion, the significance of recycling and remanufacturing in the closed-loop chain has become quite evident. This paper constructs a competitive recycling and remanufacturing model of the closed-loop supply chain through a case study of Midea Corp. and Gree Corp. and explores the impact of two recycling modes on total revenue of the supply chain and market share. The simulation results show that the total revenue of the supply chain will benefit from the increasing coverage points by the third party and the increasing environmental awareness of certain regions. The retailers show more enthusiasm of recycling through certain amendment of the contract between manufacturers and retailers. The time of payment could be shortened in closed loop. Moreover, the improvement of recycling mechanism of the retailers can enlarge the share of supply chain market. Guiding role of the proposed model and the simulation results played in establishing a better supply chain mode is presented.
\end{abstract}

\section{Introduction}

The research field of forward supply chain logistics has been widely established that concerns the economic benefits growth, the improvement of the service network, and reduction of the logistics cost. Resource recycling, environmental protection, and sustainable development have not been fully concerned. With the rapid development of modern commercial society, people consume huge amounts of natural resources, which results in waste and the eco-environmental deterioration.

Some work is still needed to develop and optimize the traditional supply chain models. Now the research on the traditional forward supply chain model is substituted by that on the whole logistics process including the product recycling, product reusing, product reprocessing, and other activities. The whole logistics process evolves into a circular structure, which is named as closed-loop supply chain. Ewaste, commonly known as electronic trash, refers to the discarded electric appliance or electronic equipment, which includes all kinds of old computers, communication equipment, TV sets, washing machines, refrigerators, and some electronic instruments and meters that are out of use. In 2014, the total of global electronic waste amounted to 41.8 million tons, and it was growing at a rate of 2 million tons per year. There were 6.033 million tons of electronic waste produced in China in 2014 and 6.5 million tons in 2015, ranking the second in the world behind the United States. China has already entered a peak of electronic scrap, with an average annual growth of $20 \%$. E-waste recycling and utilization should be developed in a sustainable way. Establishment of an effective system of electronic recycling is beneficial to the environment and general health of people. An effective system of electronic recycling is an indispensable part of development of circular economy and is the key to solving the energy problem.

At present, the main researches on the closed-loop supply chain at home and abroad are as follows. Savaskan et al. [1] comprehensively studied the selection of recycling channel of remanufacturing closed-loop supply chain by building several recycling modes. As Geyer and Jackson [2] pointed out, there were two basic goals of the implementation of closedloop supply chain management, an economic goal and an environmental goal. Guide et al. [3] presented that a closedloop supply chain should contain not only the traditional 
forward supply chain, but also the recycling reverse supply chain. Based on supply chain system performance, Fleischmann et al. [4] constructed a model of network design of closed-loop supply chain in considering enterprise strategy, tactics, and operation, respectively. Fang and Li [5] studied the resilient management problem in closed-loop supply chain network design based on competitive remanufacturers. To achieve a closed-loop supply chain coordination, Zhang et al. [6] used the theory of optimal incentive to study this problem. The result showed that the optimal retail price incentive contract could achieve closed-loop supply chain coordination in the product and sale section. Ma et al. [7] analyzed the effects of Chinese regulation policies about WEEE recycling closed-loop supply chain (CLSC) decision on electrical and electronic equipment.

In the field of recycling mode, Sun et al. [8] studied dynamic game model of remanufacturing closed-loop supply chain network over time. Xu and Song built the closed-loop supply chain competition models with recycling dominated by retailers and the third party, respectively $[9,10]$. Yao [11] pointed out that the study on management of reverse logistics with the growing consciousness of environmental protection and sustainable development should be carried on. The recycling modes could be divided into three types: the third-party leading, retailer leading, and manufacturer leading. In remanufacturing research, some theories with preliminary guidance significance were concluded through analyzing and comparing the three modes. The study on solutions comprehensively considering the combinational design and recycling and reusing the products has not been carried on. Wang and Da [12] pointed out that the producers of electronics industry were the main body to the reverse logistics mode, and they conducted a quantitative analysis on the decision models and the optimal decision about the three recycling modes. Yao et al. [13] analyzed the insufficiency of domestic recycling system, commented on the new electrical household appliances trade-in policy, and then analyzed the positive achievement and significance in standardizing the Ewaste recycling system.

In the research on supply chain optimization, Majumder and Groenevelt [14] considered a two-period competition model that the third party possessed recycling and manufacturing. Debo et al. [15] studied manufacturer's joint pricing and the selection of production technologies when the remanufacturing product had lower cost and market value. According to the three kinds of processing models (discard, resell, and reprocess), Karaer and Lee [16] studied manufacturers' recycling inventory models under the three kinds of information. Hammond and Beullens [17] built double-layer closed-loop supply chain network equilibrium model of manufacturers-consumer market by integrating forward and reverse supply chain logistics, whereas the cost of transaction within each member in the mode was not taken into account. Qiu and Huang [18] studied the closedloop supply chain with product recycling under stochastic demand. Considering two channels of the product recycling dominated by manufacturers and distributors at the same time, the manufacturers as the leaders and the retailers as the follower, Stackelberg game model of closed-loop supply chain was established. Then the possibility of coordination strategy for closed-loop supply chain channel was discussed. Ge and Huang [19] examined the joint enterprise in a two-stage closed-loop supply chain, how to determine their trade price and retail price, and how to consider the recycling price of the products in order to get an optimal profit under the situation of decentralized decision when the retailers took charge of the distribution of new product and recycling the abandoned product. A simple coordination mechanism in a closed-loop supply chain under the decentralized decision-making was put forward to improve the system efficiency. Gu et al. [20] pointed out that the reverse supply chain was different from the traditional supply chain whose pricing strategy was not applicable in the reverse supply chain. In order to solve the problem, game theory was used to study the pricing strategy of the recycling discarded products based on the reverse supply chain system formed by single manufacturer and retailer. The above three researches have failed to take into account the problem of recycling mode dominated by the third-party enterprise. Cohen et al. [21] first constructed the single-stage inventory model under assumption that the products which have been sold would be taken back with a certain proportion by the manufacturers after a period of time and provided an optimal solution. The model failed to consider the fixed cost and order lead time. Pochampally and Gupta [22] put forward a three-stage mathematical programming method for reverse logistics network design to realize the greatest economic value of the products in the process of remanufacturing. Based on the classical "selling to the newsvendor" setting, Shi et al. [23] developed a model to determine operational and financial decisions of the supply chain which comprised a manufacturer and a retailer.

In the research on recycling strategy, Golroudbary and Zahraee [24] proposed closed-loop supply chain model with system dynamics method. In this improvement system with a collection center, customer satisfaction and Green Image Factor (GIF) are considered to resolve the bottleneck problem. Mitra and Webster [25] found that government remanufacturing subsidies affected both manufacturer's profit and remanufacturer's profits. Through the comparative analysis of the three government subsidy models, manufacturers obtaining the government subsidies, remanufacturers obtaining the government subsidies, and both obtaining the government subsidies, they got the best conclusion. Chen and Sheu [26] studied the manufacturers pricing model under environmental regulation based on differential game and found out that manufacturers could implement extended producer responsibility system through appropriate pricing strategy. Yang et al. [27] put forward a universal model of closed-loop supply chain network, which was made up of raw material suppliers, manufacturers, retailers, consumers, and the recycling center. They used variation inequality to optimize the network equilibrium and studied the influence of some parameters on the order of magnitude of network equilibrium. Wang et al. [28] studied how the government's penalty policy and subsidy policy influenced the network of manufacturers and recyclers, respectively, and drew a conclusion by analyzing the parameters. Fuzzy inference and neural network in the process of the artificial intelligence 
technology were introduced into the return quantity forecast by Marx-Gómez et al. [29]. Hess and Mayhew [30] have taken the factors, such as product price, product variety, and returning reason, into consideration. They developed a regression model to predict the increasing tendency for the products.

In the above research, Savaskan represented comprehensive studies on the closed-loop supply chain model's recycling channel selection, recycling modes, and recovery strategies. Some work is still needed to develop and optimize the acrosschain competition about remanufacturing and recycling of closed-loop supply chain. The research scope is limited to the game relationship between the same-layer joints. Miao et al. [31] explored the impact on revenue and market share brought by the third-party enterprise-dominating recycling mode aiming at improving the recycling capacity of enterprise. Golroudbary and Zahraee [24] analyzed the behavior closed-loop supply chain system of an electrical manufacturing company by developing a system dynamic model. The improved model about recycling mode was constructed to solve problems stemming from pollution and unconscious use of natural resources. Their researches involve the optimization of internal supply chain, leaving the contrast of several closed-loop supply chains out of consideration. Here we construct two closed-loop supply chains competing for the same market and simulate the operation of two closed-loop supply in different remanufacturing and recycling models in the system dynamic. This paper simulates the decision-making of two remanufacturing and recycling modes, discusses the influence of model parameters on their decision, and then makes a contrast of profits and market share to provide basis for choosing the mode of the supply chain.

\section{Materials and Methods}

2.1. Description of the Case Study. Gree Corp. is the largest air-conditioning enterprise which includes products' developing manufacturing, marketing, and maintaining airconditioners all over the world. Gree has ranked first in production and marketing and market share for consecutive 12 years since 1995 . The accumulative tax since 1991 is 4.25 billion RMB. The sales revenue in 2006 reached 23.803 billion $\mathrm{RMB}$. The sales volume of the domestic air-conditioners reached 13 million $\mathrm{RMB}$, ranking the first in the world for two years in a row. Midea Corp. was established in 1968 as a modern enterprise focusing on household appliances and logistics. It is one of the biggest environmentally friendly manufacturers which produce air-conditioners, refrigerators, and kitchen aids and other kinds of small house appliance. Midea Corp. was the only nominated household appliance enterprise in the most valuable 500 brand ranking lists published by "Brand Finance": international authoritative British brand consultant institution. The competition between Gree Corp. and Midea Corp. is constant. Gree Corp. used to consistently specialize in air-condition manufacturing while Midea Corp. continued to seek product diversification. Under the guidance of "low-Carbon, Ecolife" policy published by Chinese government, Gree Corp. and Midea Corp. and other

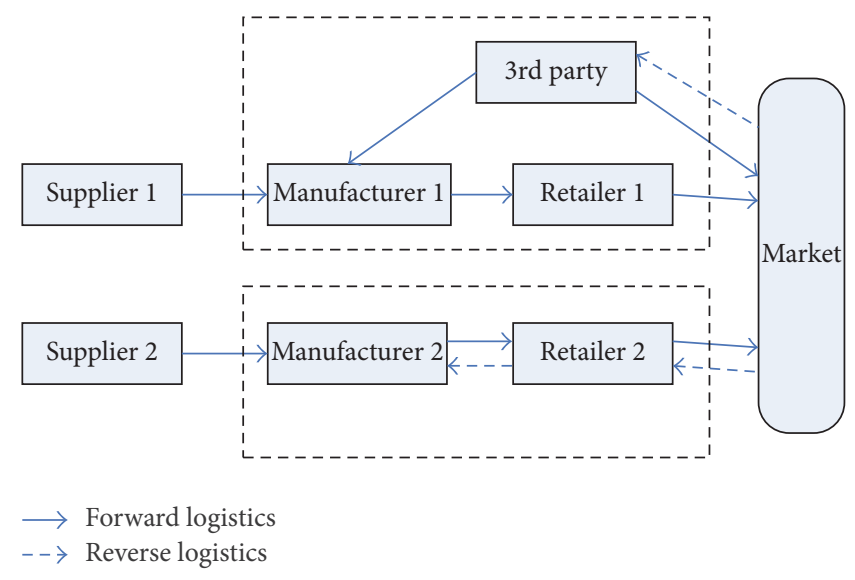

FIGURE 1: Recycling competition structure model.

corporations start new programs to recycle and remanufacture their own household appliances in different recycling modes and tactics. This paper constructs a mode in which Gree Corp. and Midea Corp. are competing with each other. In addition, the impact of recycling modes and recycling strategies on enterprises competitiveness is analyzed by comparing two recycling modes applied by the two enterprises.

2.2. The Construction of Competition Model. Midea Corp. and Gree Corp. are competing in the same market. In this model, Midea Corp. is operated as supply chain 1. Supply chain 1 works as follows: the division of labor and cooperation among manufacturers, retailers, and third party. The duties of manufacturers and retailers and third-party enterprise are the production and the sale of electronic products and the recycling and sorting of waste electronic products, respectively. Gree Corp. is operated as supply chain 2. Supply chain 2 is running through the cooperation of the manufacturers and retailers. The duty of manufacturers is producing electronics, while the duty of retailers includes selling the products and recycling and sorting the waste electronic products (Figure 1).

The recycling mode of supply chain 1 is third-party enterprises leading. After the retailers sell the products to the market, recycling and disposing will be conducted by the third-party enterprises. Normally, the E-waste is treated by the third-party enterprises in two ways. Some E-waste is returned to the manufacturer and disassembled into components which would be remanufactured; the rest of the products are sold as second-hand goods. In this mode, the manufacturers, the retailers, and the third-party enterprises are responsible for the production, sales, and recycling, separately. This mode can promote the specialization in the close-loop supply chain running to the greatest extent and formation of scale effect. At the same time, it is worth noting that the third-party enterprises take many approaches to recycle the E-waste, such as street vendors, settled recycling site, and indirectly recycling through repair sites. There are many factors that can influence the productivity of the independent E-waste recycling of the third-party enterprises, 


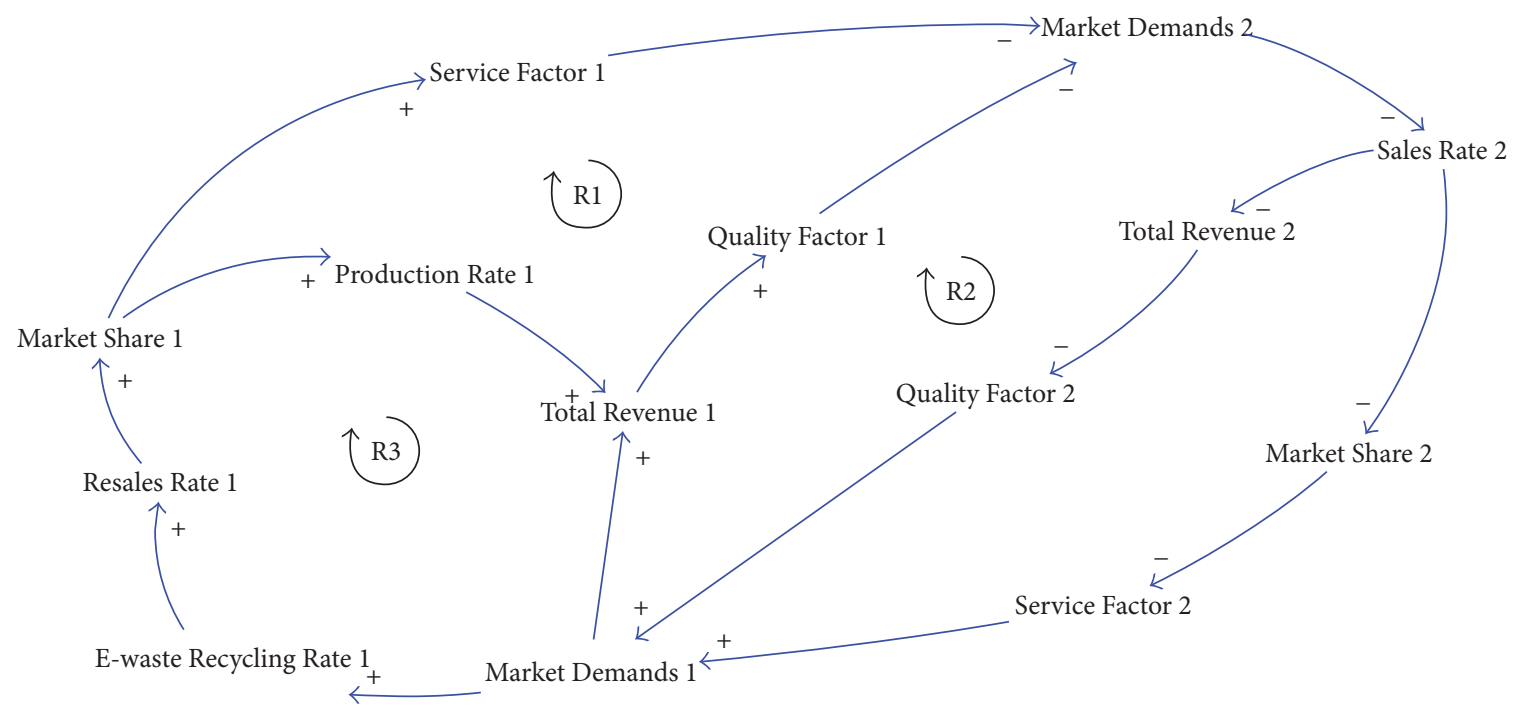

FIgURE 2: Casual loop diagram of across-chain competition.

such as recycling point coverage rate and environmental protection consciousness of consumers. The recycling inventory can be adjusted according to the trading volume of the Ewaste in the local market. After simple treatment of the recycled E-waste, the third-party enterprise can optimize and distribute the E-waste to maximize the interests of the whole supply chain.

The recycling mode of supply chain 2 is retailers leading. After the retailers sell the products to the market, recycling of E-waste will be conducted by themselves and they will return the E-waste to the manufacturer directly. There are two ways of dealing with the E-waste: the portion that can be remanufactured will be returned to the manufacturer and the portion that cannot be used will be disposed. In this mode, the manufacturer reaches an agreement with retailers. As the main body of the recycling model, retailers play a role of connecting manufacturers and market. They take charge of product sales and recycling, while the manufacturers only need to have charge of product manufacturing and remanufacturing and giving the retailer a certain economic compensation in recycling.

The recycling mode dominated by retailers is commonly used in the electronics industry, even in the household papers industry. The main advantage of this model lies in the market demand information collection and response of the supply chain. Retailers are the closest part to the customers in the supply chain, and only they can obtain the information of the market demand directly. If the retailers are considered as the recycling core of the supply chain, the process and response to the demand information in the supply chain will be faster. Since retailers grasp the real-time demand information, their decisions on the various supply chain management are more rational. There is a trend that the consumer's position will be more and more important. In this case, the recycling model dominated by retailer will gain greater development.
Li et al. [32] chose Dell Computers Corp. as a case study to examine the impact of direct distributor's return policy and the quality policy on the return decisions by developing several theoretical models, which described that return is sensitive to quality. This paper assumes that consumer's choice determines market demand. Because the retailers and the third party serve the consumer market, sales and status of recycling are the most direct factors to evaluate the competitiveness of the whole supply chain. Consumer's choice (including second-hand products) is the evaluation of the operation of the whole supply chain. The competiveness of supply chains is evaluated based on two key factors of quality and service, which are quantified as the key parameters to predict consumers' choice. In the model of supply chain competitiveness, the node members such as manufacturers, retailers, and the third-party enterprises separately adopt different optimization methods such as adjusting strategy, improving recycling ability, and changing the collection points coverage rate. By adjusting the related parameters in the model of system dynamics, this study makes profit and market share of supply chains optimal and makes supply chains achieve a competitive advantage in the across-chain competition.

2.3. System Dynamics Modeling Hypotheses. System dynamics is a discipline of close integration of scientific theory and computer simulation, comprising feedback structure of research system and behavior. The method is the combination of qualitative and quantitative research and the method of system comprehensive inference. Its modeling process is a combination of learning, investigation, and research.

A causal loop diagram is used to reflect the correlation between elements and the feedback process of the system. In this analysis, the author considers the influential factors of each node in the closed-loop supply chain and establishes a causal loop diagram in Figure 2. 
(R1) Resales Rate $1 \uparrow \rightarrow$ Market Share $1 \uparrow \rightarrow$ Service Factor $1 \uparrow \rightarrow$ Market Demands $2 \downarrow \rightarrow$ Sales Rate $2 \downarrow \rightarrow$ Market Share $2 \downarrow \rightarrow$ Service Factor $2 \downarrow \rightarrow$ Market Demands $1 \uparrow$ $\rightarrow$ E-waste Recycling Rate $1 \uparrow \rightarrow$ Resales Rate $1 \uparrow$

(R1) is a causal loop of across-chain. Compared with the recycling mode dominated by the retailers, the recycling mode dominated by the third party has more choices to dispose the reusable products in the case of equal market share of both supply chains. In this mode, resale activities can expand Market Share 1, so as to improve Market Demands 1.

(R2) Market Demands $1 \uparrow \rightarrow$ Total Revenue $1 \uparrow \rightarrow$ Quality Factor $1 \uparrow \rightarrow$ Market Demands $2 \downarrow \rightarrow$ Sales Rate $2 \downarrow$ $\rightarrow$ Total Revenue $2 \downarrow \rightarrow$ Quality Factor $2 \downarrow \rightarrow$ Market Demands $1 \uparrow$

(R2) is a causal loop of across-chain. Since the Total Market Demands is fixed, the increasing of Market Demands 1 of the recycling mode dominated by third-party enterprise can promote Total Revenue 1 and Quality Factor 1, while this will affect the Sales Rate 2 of electronic products in the recycling mode dominated by retailers and therefore reduce its market competitiveness.

(R3) Production Rate $1 \uparrow \rightarrow$ E-waste Recycling Rate $1 \uparrow \rightarrow$ Resales Rate $1 \uparrow \rightarrow$ Market Share $1 \uparrow \rightarrow$ Production Rate $1 \uparrow$

(R3) is an internal causal loop of the recycling mode dominated by third-party enterprise. Increasing Production Rate 1 to promote the efficiency of production and sales of electronic products makes the amount of waste electronic products increased in the market. The recycling rate will be improved correspondingly by recyclers and therefore promote the Resales Rate 1 of waste electronic products and improve the Market Share 1.

Then we establish the system dynamics model based on supply chain competition, in which recycling and remanufacturing of two corporations are taken as example. The two different kinds of recycling dominant models are illustrated and compared in Figure 3.

Since the third party is introduced to dominate the recycling in the supply chain 1 , the smoothness of the closedloop supply chain depends to a great extent of the third party's recycling ability. Figure 4 shows the third party's recycling mechanism. There is a trend that the consumer's position in the supply chain will get more and more important; many scholars also study the influence of consumer behavior on supply chain. Lao [33] constructed the hypothesis model of consumers innovative influence on green consumption behavior. Tian and Yuan [34] proposed a conceptual model to explain the relationship between corporate social responsibility fit and consumer brand attitude. In this study, we studied the impact of environmental consciousness of consumers on the E-waste recycling. Consumers with strong environmental protection awareness are more inclined to rationally handle old electronics and turn them into value rather than directly discard them. Strong environmental protection awareness will accelerate the transfer rate of the reverse logistics and promote the processing efficiency of the third party. Collection Points Coverage Rate and Processing Capacity also play an active role in the closed-loop system of supply chain 1. The dense distribution of the collection agencies helps increase the regional low-carbon level and remanufacturing cycle efficiency.

For the supply chain 2, because of recycling costs in the recycling dominated by retailers, manufacturers need to develop appropriate incentive strategy and establish a contract to motivate retailers in recycling efforts. The contract structure flow diagram is shown in Figure 5. The recycling contract between manufacturers and retailers is as follows:

Manufacturer Incentive Coefficient = IF THEN ELSE (Retailers Recycling Inventory $<=(0.8 *$ E-waste), IF THEN ELSE (Retailers Recycling Inventory <= (0.5* E-waste), IF THEN ELSE (Retailers Recycling Inventory $<=(0.3 *$ E-waste $), 0.1,0.2), 0.3), 0.5)$.

While Retailers Recycling Inventory $<=0.3 *$ E-waste, Manufacturer Incentive Coefficient $=0.1$;

While $0.3 *$ E-waste < Retailers Recycling Inventory $<=0.5 *$ E-waste, Manufacturer Incentive Coefficient $=0.2$;

While $0.5 * E$-waste < Retailers Recycling Inventory $<=0.8 *$ E-waste, Manufacturer Incentive Coefficient $=0.3$;

While Retailers Recycling Inventory $>=0.8 *$ E-waste, Manufacturer Incentive Coefficient $=0.5$.

Retailers Recycling Enthusiasm = Effect Degree $*$ Manufacturer Incentive Coefficient.

In this contract, the Manufacturer Incentive Coefficient of manufacturers to retailers is determined by the proportion of Retailers Recycling Inventory in the E-waste. The greater the proportion of the value, the higher the Manufacturer Incentive Coefficient of manufacturers to retailers. The two sides have a linear proportional relationship. Retailers Recycling Enthusiasm will also grow. Adjusting the Effect Degree can also affect Retailers Recycling Enthusiasm. With the improvement of Retailers Recycling Enthusiasm, the E-waste circulating in the market will also be reduced relatively.

2.4. The Major Parameters and Equation of the Model. Assuming that the demand of household appliance complied with the normal distribution in the E-waste recycling system supply chain, the Market Demand = RANDOM NORMAL (1, $1000,100,100,2)$.

Some constants are set as follows (Table 1). 


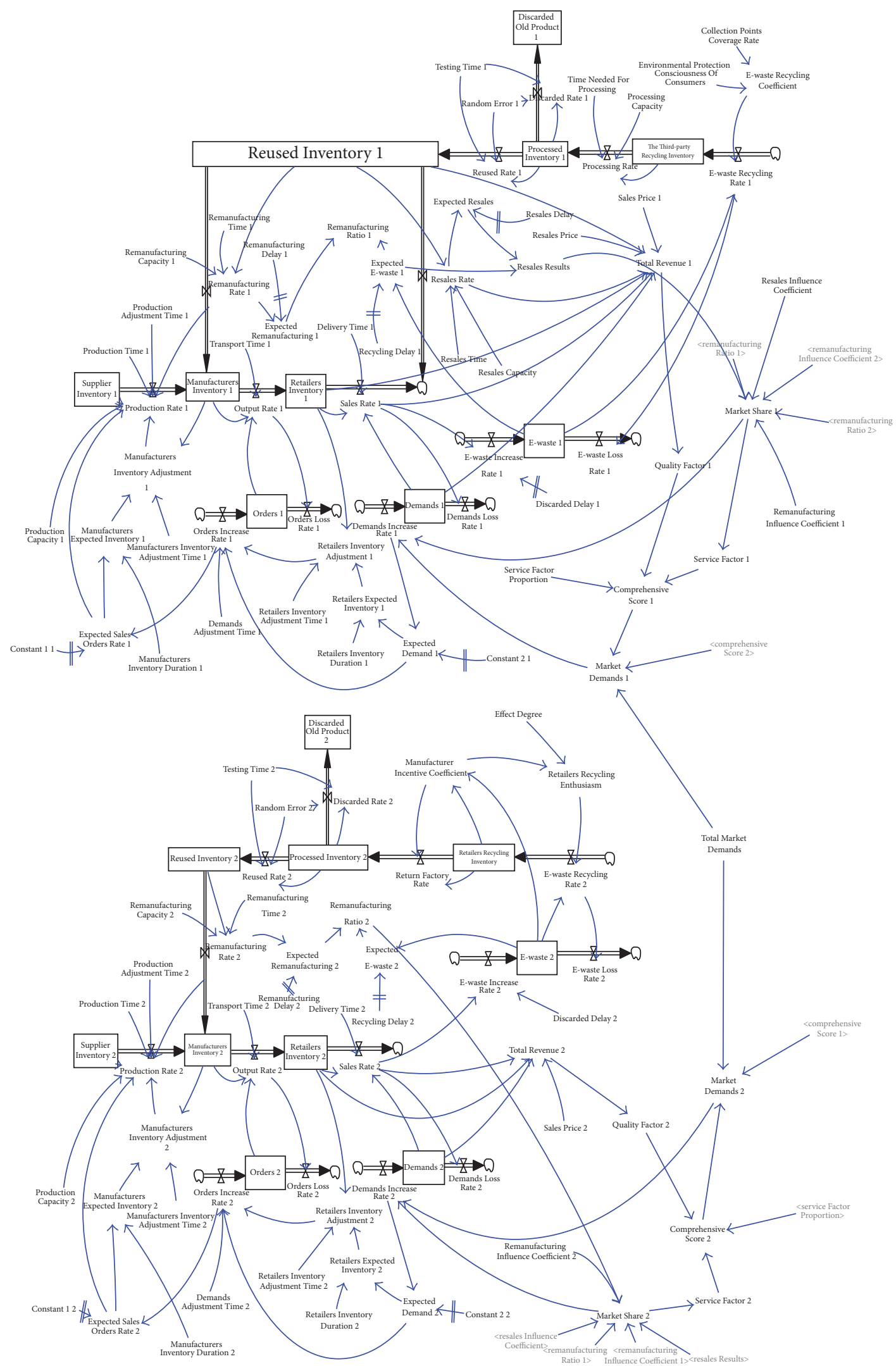

Figure 3: Across-chain competition system dynamics model. 
The main function relational expression:

Production Rate $1=\max \left(\min \left(\right.\right.$ Production Capacity $1, \min \left(\frac{\text { Supplier Inventory } 1}{\text { Production Time } 1}\right.$,

$\min \left(\right.$ Expected Sales Orders Rate 1-Remanufacturing Rate 1, $\left.\left.\frac{\text { Manufacturers Inventory Adjustment 1 }}{\text { Production Adjustment Time } 1}\right)\right)$

$0)$.

Under recycling model dominated by the third party, considering the influence of Remanufacturing Rate 1 ,

Manufacturer Inventory 1

$=\int_{t 0}^{t}$ (Remanufacturing Rate 1

+ Production Rate 1-Output Rate 1) $d t$,

Retailers Inventory $1=\int_{t 0}^{t}$ (Output Rate 1

- Sales Rate 1) dt.

Output Rate 1 is the ratio of the smaller value of Manufacturers Inventory 1 and Orders 1 to Transport Time 1, while Sales Rate 1 is the ratio of the smaller value of Retailers Inventory 1 and Demands to Delivery Time 1.

$$
\text { Orders } 1=\int_{t 0}^{t}(\text { Orders Increase Rate } 1
$$

- Orders Loss Rate 1) $d t$,

Demands $1=\int_{t 0}^{t}($ Demands Increase Rate 1

\section{- Demands Loss Rate 1) dt.}

Orders Increase Rate 1 is the ratio of the smaller value of Expected Demands 1 and Retailers Adjustment Inventory 1 to Demands Adjustment Time 1, and Order Loss Rate 1 is equal to Output Rate 1.

\section{Demands Increase Rate 1}

$$
\text { = Market Demands } 1 *(1+\text { Market Share } 1) \text {. }
$$

And Demands Loss Rate 1 is equal to Sales Rate 1.

Considering there will be a certain delay from electronic products to E-waste in the market, we use SMOOTH (Sales Rate 1, Discarded delay 1) to represent the E-waste Increase
Rate 1, while E-waste Loss Rate 1 is equal to E-waste Recycling Rate 1.

$$
\begin{aligned}
& \text { The Third-Party Recycling Inventory } 1 \\
& =\int_{t 0}^{t}(\text { E-waste Recycling Rate } 1 \\
& - \text { Processing Rate }) d t .
\end{aligned}
$$

E-waste Recycling Rate 1 is equal to the product of Ewaste Recycling Coefficient and E-waste 1. In real life, the E-waste recycling situation also involves Collection Points Coverage Rate and Environmental Protection Consciousness of Consumers.

$$
\begin{aligned}
& \text { E-waste Recycling Coefficient } \\
& =\text { Collection Points Coverage Rate } \\
& \text { * Environmental Protection Consciousness of Consumers, } \\
& \text { E-waste Recycling Rate } 2 \text { = Retailers Recycling Enthusiasm } \\
& \text { * E-waste 2. }
\end{aligned}
$$

Considering the third-party recycling for E-waste is limited by the Time Needed for Processing and Processing Capacity, we define the following:

$$
\begin{aligned}
& \text { Processing Rate } \\
& \left.\qquad \begin{array}{l}
\text { The Third-Party Recycling Inventory } \\
\text { Time Needed for Processing }
\end{array}\right) \\
& \quad \text { * Processing Capacity. }
\end{aligned}
$$

Discarded Rate 1 depends on the multiplication of Processed Inventory and Random Error 1/Testing Time 1, while 


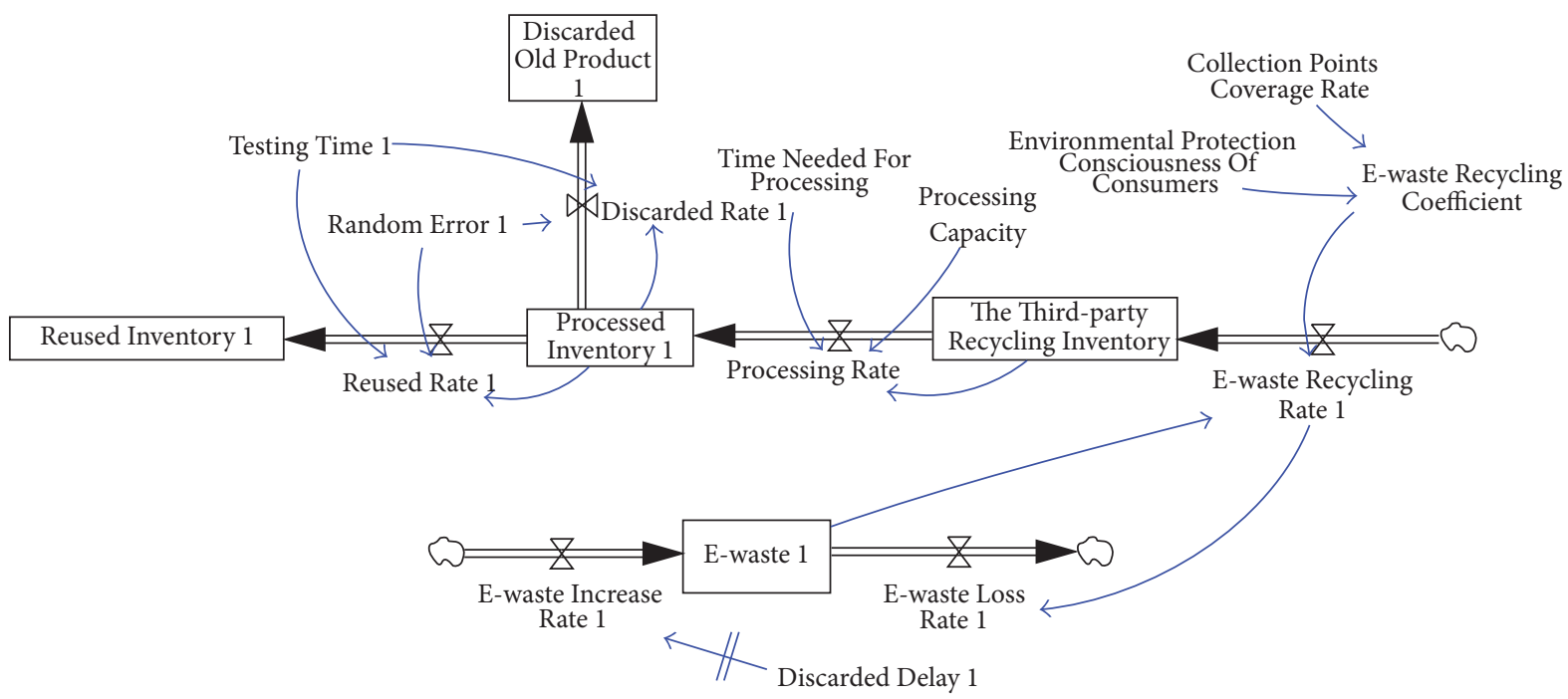

FIGURE 4: The third-party recycling mechanism flow diagram.

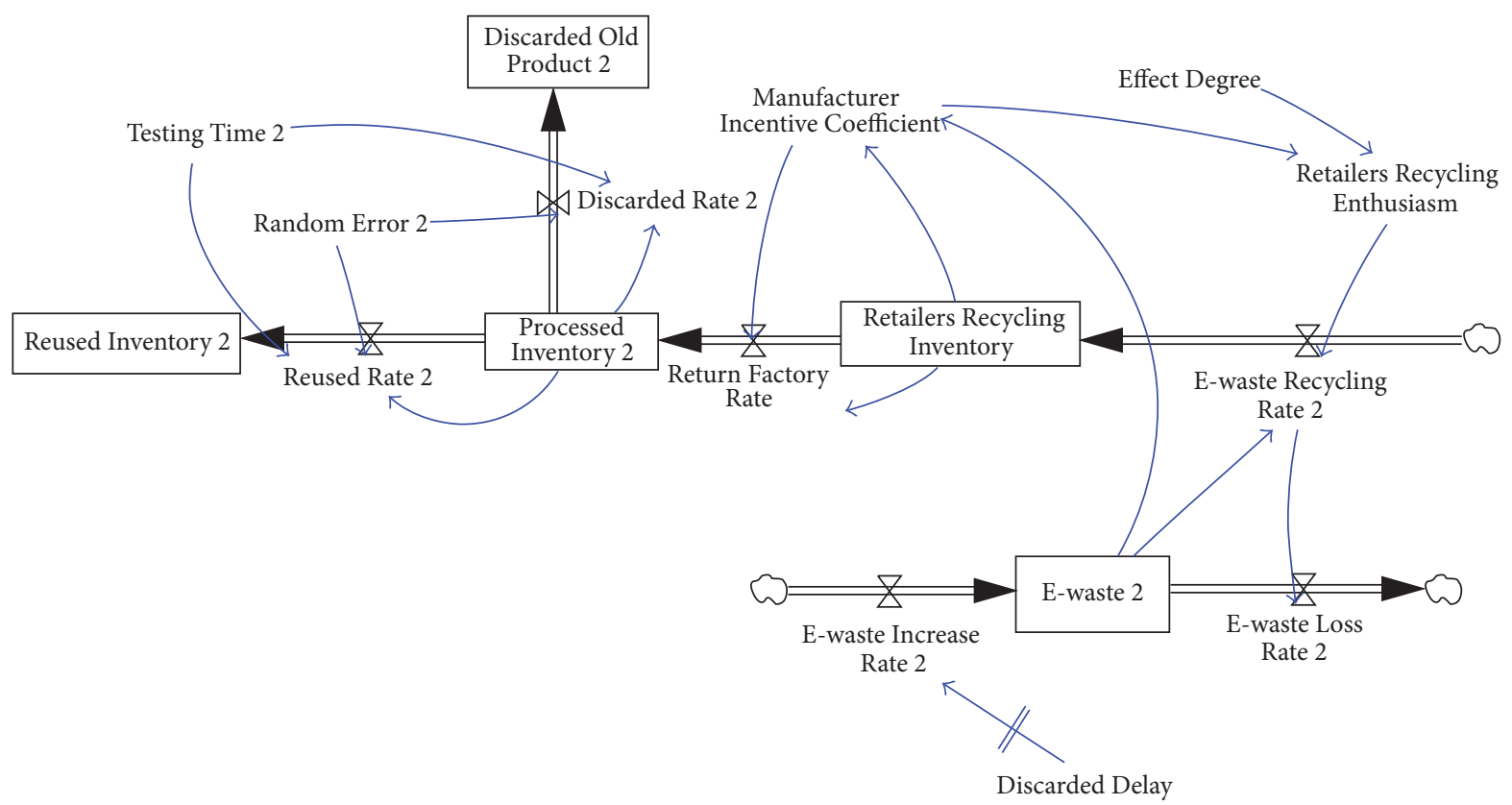

FIGURE 5: Contract structure flow diagram.

Reused Rate 1 depends on the multiplication of Processed Inventory and (1-Random Error 1/Testing Time 1).

Processed Inventory $=\int_{t 0}^{t}$ (Processing Rate

- Discarded Rate 1-Reused Rate 1) dt,

Reused Inventory $=\int_{t 0}^{t}$ (Reused Rate 1

- Resales Rate - Remanufacturing Rate 1) $d t$,

Discarded Old Product

$=\int_{t 0}^{t}($ Discarded Rate 1) $d t$
One part of E-waste can be resold and another needs to be returned for remanufacturing in Reused Inventory. Thus we set the following:

\section{Remanufacturing Rate 1}

$$
=\left(0.6 * \frac{\text { Reused Inventory } 1}{\text { Remanufacturing Time 1 }}\right)
$$

$$
\text { * Remanufacturing capacity } 1 \text {, }
$$

\section{Resales Rate}

$$
=\left(0.4 * \frac{\text { Reused Inventory } 1}{\text { Resales Time }}\right)
$$

* Resales Capacity. 
TABLE 1: Constants set.

\begin{tabular}{|c|c|}
\hline Parameter & value \\
\hline Production Time 1 & 2 \\
\hline Demands Adjustment Time 2 & 2 \\
\hline Sales Price & 10 \\
\hline Random Error 1 & 0.2 \\
\hline Manufacturers Inventory Adjustment Time 2 & 12 \\
\hline Manufacturers Inventory Duration 1 & 12 \\
\hline Resales Influence Coefficient & 0.2 \\
\hline Time Needed for Processing & 6.5 \\
\hline Effect Degree & 0.5 \\
\hline Resales Capacity & 0.3 \\
\hline Testing Time 1 & 1 \\
\hline Remanufacturing Capacity 2 & 0.36 \\
\hline Delivery Time 1 & 1 \\
\hline Production Adjustment Time 2 & 2 \\
\hline Transport Time 1 & 1 \\
\hline Constants 1, 2, 3 & 12 \\
\hline Remanufacturing Delay 1 & 48 \\
\hline Retailers Inventory Adjustment Time 1 & 12 \\
\hline Retailers Inventory Duration 2 & 1.2 \\
\hline Remanufacturing Influence Coefficient 1 & 0.3 \\
\hline Processing Capacity & 0.64 \\
\hline Recycling Delay 2 & 48 \\
\hline Resales Delay & 5 \\
\hline Discarded Delay 1 & 10 \\
\hline Remanufacturing Time 1 & 1.2 \\
\hline Production Capacity 1 & 10 \\
\hline
\end{tabular}

The simulation time length: initial time $=0$ weeks, final time $=100$ weeks, and time step $=1$ week; the simulation cycle is 100 weeks, a week for a step.

Remanufacturing Ratio 1 is the ratio of Expected Remanufacturing 1 to Expected E-waste 1, while Resales Results is the ratio of Expected Resales to Expected E-waste 1.

Expected E-waste 1, Expected recycling 1, Expected Resales, and Expected remanufacturing 1 are, respectively, decided by E-waste 1, E-waste Increasing Rate 1, Resales Rate, and Remanufacturing Rate 1 and their corresponding delay time under the SMOOTH.

Total Revenue 1 mainly consists of resale revenue and sales income:

Total Revenue $1=0.4 *$ Reused Inventory 1

* Resales Rate * Resales price

$+\min ($ Retailers Inventory 1, Demands 1)

* Sales Price $1 *$ Sales Rate 1 ,

Total Revenue 2

$=\min ($ Retailers Inventory 2, Demands 2$)$

* Sales Price $2 *$ Sales Rate 2,
Market Share 1

$=($ Remanufacturing Influence Coefficient 1

* Remanufacturing Ratio 1+ Resales Results

* Resales Influence Coefficient 1)

- (Remanufacturing Influence Coefficient 1

* Remanufacturing Ratio 1+ Resales Results

* Resales Influence Coefficient 1

+ Remanufacturing Influence Coefficient 2

* Remanufacturing Ratio $2+0.01)^{-1}$,

Market Share 2

$=($ Remanufacturing Influence Coefficient 2

* Remanufacturing Ratio 2)

- (Remanufacturing Influence Coefficient 1

* Remanufacturing Ratio 1+ Resales Results

* Resales Influence Coefficient 1

+ Remanufacturing Influence Coefficient 2

* Remanufacturing Ratio $2+0.01)^{-1}$,

Comprehensive Score 1 = Service Factor 1

* Service Factor Proportion + Quality Factor $1 *(1$

- Service Factor Proportion),

Comprehensive Score 2 = Service Factor 2

* Service Factor Proportion + Quality Factor $2 *(1$

- Service Factor Proportion),

Market Demands 1

$$
=\frac{(\text { Total Market Demands } * \text { Comprehensive Score } 1)}{(\text { Comprehensive Score } 1+\text { Comprehensive Score } 2)},
$$

Market Demands 2

$$
=\frac{(\text { Total Market Demands } * \text { Comprehensive Score } 2)}{(\text { Comprehensive Score } 1+\text { Comprehensive Score } 2)} \text {. }
$$

\section{Simulation and Analysis}

The two different recycling modes of the supply chains lead to different reverse logistics paths. Thus the Total Revenue of each chain must be different. To adjust the total revenue of the two supply chains to the same range, the Collection Points Coverage Rate is set to 0.75 , the Environmental Protection Consciousness of Consumers to 0.2, the Effect Degree 


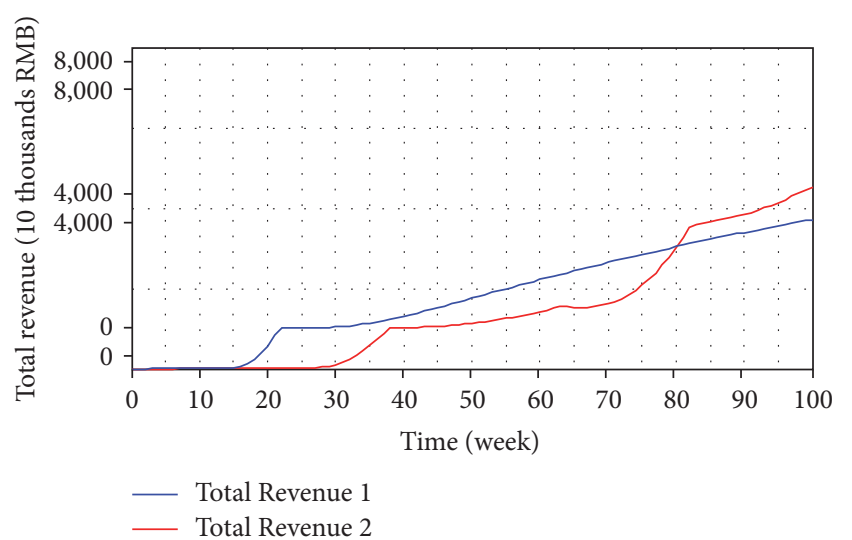

FIgure 6: Total Revenue contrast 1.

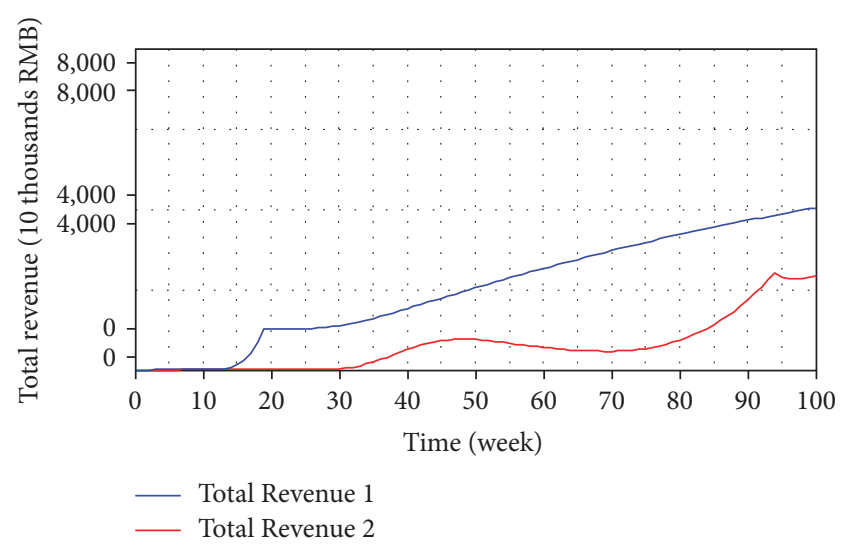

Figure 7: Total Revenue contrast 2.

of Manufacturer Incentive Coefficient to 0.4875, and the Processing Capacity of the third-party enterprise to 0.64. Figure 6 shows the comparison of the two supply chains' Total Revenue resulting from the simulation. In supply chain 1, Total Revenue begins to appear in the 15th week while in supply chain 2 it begins to appear from the 28 th week. This is because there are delays in the process of production, sales, recycling, and so on. Therefore, at the early stage of the whole cycle, the Total Revenue is 0. The Total Revenue of supply chain 1 is higher than that of supply chain 2 until the 80 th week. After that, Supply chain 2 begins to surpass supply chain 1 a little. As a whole, the tendency of the two Total Revenue values are basically identical.

In order to improve the Total Revenue, the third-party enterprises of the supply chain 1 improve their recycling ability, thus enhancing the Environmental Protection Consciousness of Consumers from 0.2 to 0.4 . The third-party enterprises or the government can promote the awareness of environmental protection to make the customers in this area sort and process the waste electronic products consciously. Although these measures will also indirectly increase the retailers recycling efficiency of supply chain 2, the Total Revenue of supply chain 1 is still more profitable as a result of the high coverage of the third-party collection points in supply chain 1 . The simulation result is shown in Figure 7.

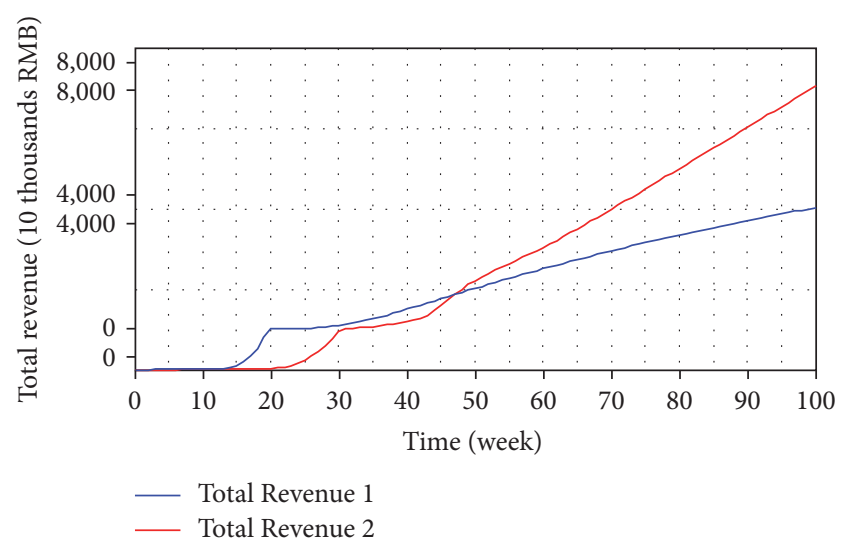

Figure 8: Total Revenue contrast 3.

Since its interest is hurt, supply chain 2 decides to make adjustments on the recycling strategy. In supply chain 2 retailers dominate the recycling. We can improve Retailers Recycling Enthusiasm from two aspects. On one hand, the manufacturer can adjust its incentive strategy by raising the repurchase price to push the retailer recycle more. On the other hand, the manufacturer can improve the Effect Degree, namely, introducing the government support mechanism, to support enterprises to carry out the effective recycling from the perspective of environmental protection. The recycling contract between manufacturers and retailers is adjusted as follows.

Manufacturer Incentive Coefficient = IF THEN ELSE (Retailers Recycling Inventory $<=(0.8 * E$-waste), IF THEN ELSE (Retailers Recycling Inventory $<=(0.5 *$ E-waste), IF THEN ELSE (Retailers Recycling Inventory $<=(0.3 * E$-waste $)$, $0.2,0.3), 0.4), 0.6)$. The simulation result is shown in Figure 8.

As can be seen from Figure 8, the Total Revenue of supply chain 2 is obviously improved and goes beyond the supply chain 1 in the 48th week. The closed loop between manufacturers and retailers enhances the efficiency of forward logistics and reverse logistics flow, which shortens the delivery delay of the upper stream. Thus, not only is the Total Revenue increased, but also the payment delay is shortened. Supply chain 2 begins to be profitable in the 22 nd week which used to be the 30th week. It is similar to the case that the Effect Degree is improved through government support.

Two supply chains' market demand is determined by the quality and service. The functional relationship between Total Revenue and Quality Factor and between Market Share and Service Factor, that is, Total Revenue and Quality Factor and Market Share and Service Factor, is linear direct proportion. These factors promote each other and jointly determine the Market Demands. Figure 9 shows that although the Total Revenue of supply chain 2 exceeds the supply chain 1 from the 48th week, its Market Share is not dominant. In order to make a change, supply chain 2 decides to increase the Remanufacturing Influence Coefficient to 0.7; that is, retailers formulate the trade-in policy and the price-difference swap policy. The simulation result is shown in Figure 10. 


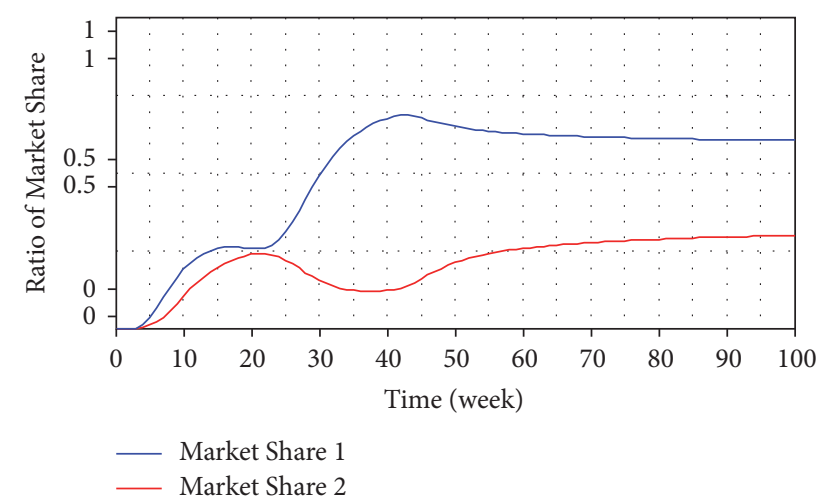

FIGURE 9: Market Share contrast 1.

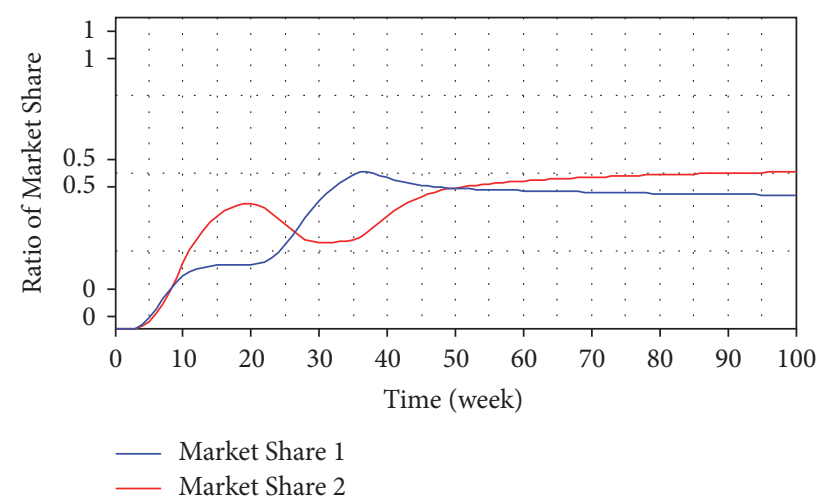

FIGURE 10: Market Share contrast 2.

\section{Conclusions}

The competitions of traditional supply chains are out of date with the maturity and development of manufacturing industry. The new competing mode of recycling and remanufacturing arises. To study the structures of the two recycling modes, this paper constructs the recycling and remanufacturing model in which Gree Corp. supply chain and Midea Corp. supply chain compete. The effects of two modes on the total revenue of the supply chains and market share are simulated by the method of system dynamics. Unprecedentedly, this paper simulates a condition that two three-step closed-loop supply chains compete for the same market. The third-party recycling supply chain and retailer recycling supply chain construct two closed loops, respectively. The optimal strategies of these two supply chains are proposed after adjusting the system parameters, respectively. This paper provides a theoretical guidance for the choosing of supply chain recycling mode. The conclusion involves fours aspects:

(1) More recycle point coverage will boost the total profit of the supply chain within the scope of the third-party manufacturing ability.

(2) The publicity of low-carbon lifestyle raises the regional consumers' awareness at the expense of increasing cost.
(3) The retailer's initiative to recycle could be encouraged to renew the contract between manufacturers and retailers. The speed of the product circulating on the manufacturer-retailer market closed loop is hastened and the delay time of the payment is shortened at the cost of manufacturer's giving up some profits.

(4) A better recycling mechanism of the retailers will lead to more market share of the supply chain.

The model provided here is based on conditional hypothesis. The follow-up study should involve robustness and universality and extend the two-recycling-mode competition to several-recycling-mode competition.

\section{Conflicts of Interest}

The authors declare that they have no conflicts of interest.

\section{Acknowledgments}

This work was supported by the Hei Long Jiang Postdoctoral Foundation (no. LBH-Z5100) and the Foundation of Heilongjiang Educational Committee (no. 12541108). The authors thank all project partners for their valuable contributions and feedback.

\section{References}

[1] R. C. Savaskan, S. Bhattacharya, and L. N. Van Wassenhove, "Channel choice and coordination in a remanufacturing environment," INSEAD, 2000.

[2] R. Geyer and T. Jackson, "Supply loops and their constraints: the industrial ecology of recycling and reuse," California Management Review, vol. 46, no. 2, pp. 55-73, 2004.

[3] V. D. R. Guide Jr., M. E. Kraus, and R. Srivastava, "Scheduling policies for remanufacturing," International Journal of Production Economics, vol. 48, no. 2, pp. 187-204, 1997.

[4] M. Fleischmann, R. Kuik, and R. Dekker, "Controlling inventories with stochastic item returns: a basic model," European Journal of Operational Research, vol. 138, no. 1, pp. 63-75, 2002.

[5] H. W. Fang and H. J. Li, "Network design and resilient management research on closed-loop supply chain in electronics industry," Comput. Eng. Appl, vol. 53, no. 9, pp. 263-270, 2017.

[6] H. J. Zhang, X. Gan, and M. Y. Lai, "Coordination of closed-loop supply chain with the optimal price and recycle effort incentive contract," J. Syst. Eng, vol. 30, no. 2, pp. 201-209, 2015.

[7] Z. J. Ma, S. Hu, and Y. Dai, "Closed-loop supply chain decision for electrical and electronic equipments under government regulations," Ind. Eng. Manage, vol. 21, no. 1, pp. 45-51, 2016.

[8] J. Y. Sun, C. X. Teng, and Z. B. Chen, "Dynamic model of closedloop supply chain network with product remanufacturing based on differential variational inequality," Syst. Eng. Theory Pract, vol. 35, no. 5, pp. 1155-1164, 2015.

[9] B. Xu and J. M. Yang, "Research on competition between two closed-loop supply chains and coordination within one closedloop supply chain under stochastic demand," J. Nanchang Univ. (Eng. \&amp; Technol.), vol. 34, no. 3, pp. 300-306, 2012.

[10] M. Song, M. Huang, and X. W. Wang, "Selection strategies of channel structure for competing closed-loop supply chains," Control. and Decis, vol. 28, no. 8, pp. 1247-1252, 2013. 
[11] W. X. Yao, "Comparison of different take-back models in reverse logistics," Manag. Sci, vol. 17, no. 01, pp. 76-79, 2004.

[12] F. H. Wang and Q. L. Da, "The decision-making analysis in deciding reverse logistics system with remanufacturing in electronic industry," J. Manag. Sci. China, vol. 14, no. 6, pp. 4449, 2006.

[13] L. L. Yao, W. Z. He, G. M. Li, S. G. Zhu, and G. W. Huang, "Current development status of WEEE recycling and management in China," Environ. Sci. Technol, vol. S1, pp. 410-414, 2012.

[14] P. Majumder and H. Groenevelt, "Competition in remanufacturing," Production and Operations Management, vol. 10, no. 2, pp. 125-141, 2001.

[15] L. G. Debo, L. B. Toktay, and L. N. van Wassenhove, "Market segmentation and product technology selection for remanufacturable products," Management Science, vol. 51, no. 8, pp. 11931205, 2005.

[16] Ö. Karaer and H. L. Lee, "Managing the reverse channel with RFID-enabled negative demand information," Production and Operations Management, vol. 16, no. 5, pp. 625-645, 2007.

[17] D. Hammond and P. Beullens, "Closed-loop supply chain network equilibrium under legislation," European Journal of Operational Research, vol. 183, no. 2, pp. 895-908, 2007.

[18] R. Z. Qiu and X. Y. Huang, "Coordination model for closedloop supply chain with product recycling," J. Northeast. Univ. (Nat. Sci. Ed.), vol. 28, no. 6, pp. 883-886, 2007.

[19] J. Y. Ge and P. Q. Huang, "Closed-loop supply chain coordination research based on game theory," J. Syst. Manag, vol. 16, no. 05, pp. 549-552, 2007.

[20] Q. L. Gu, T. G. Gao, and L. S. Shi, "Price decision analysis for reverse supply chain based on game theory," J. Syst. Eng. Theory Pract, vol. 25, no. 3, pp. 20-25, 2005.

[21] M. A. Cohen, W. P. Pierskalla, and S. Nahmias, "A dynamic inventory system with recycling," Naval Research Logistics Quarterly, vol. 27, no. 2, pp. 289-296, 1980.

[22] K. K. Pochampally and S. M. Gupta, "Strategic planning of a reverse supply chain network," International Journal of Integrated Supply Management, vol. 1, no. 4, pp. 421-441, 2005.

[23] D. Shi, Y. Li, and X. Cai, "Optimal operational decisions when a manufacturer offers trade credit to his retailer," Journal of Systems Science and Systems Engineering, vol. 21, no. 4, pp. 480496, 2012.

[24] S. R. Golroudbary and S. M. Zahraee, "System dynamics model for optimizing the recycling and collection of waste material in a closed-loop supply chain," Simulation Modelling Practice and Theory, vol. 53, article no. 1481, pp. 88-102, 2015.

[25] S. Mitra and S. Webster, "Competition in remanufacturing and the effects of government subsidies," International Journal of Production Economics, vol. 111, no. 2, pp. 287-298, 2008.

[26] Y. J. Chen and J.-B. Sheu, "Environmental-regulation pricing strategies for green supply chain management," Transportation Research Part E: Logistics and Transportation Review, vol. 45, no. 5, pp. 667-677, 2009.

[27] G. Yang, Z. Wang, and X. Li, “The optimization of the closedloop supply chain network," Transportation Research E, vol. 45, no. 1, pp. 16-28, 2009.

[28] W. B. Wang, Q. L. Da, T. B. Hu, and G. F. Yang, "Remanufacturing closed-loop supply chain network equilibrium model based on allowance and penalty," Oper. Res. Manag. Sci, vol. 19, no. 1, pp. 65-72, 2010.

[29] J. Marx-Gómez, C. Rautenstrauch, A. Nürnberger, and R. Kruse, "Neuro-fuzzy approach to forecast returns of scrapped products to recycling and remanufacturing," Knowledge-Based Systems, vol. 15, no. 1-2, pp. 119-128, 2002.

[30] J. D. Hess and G. E. Mayhew, "Modeling merchandise returns in direct marketing," Journal of Interactive Marketing, vol. 11, no. 2, pp. 20-35, 1997.

[31] S. Miao, T. Wang, and D. Chen, "System dynamics research of remanufacturing closed-loop supply chain dominated by the third party," Waste Management \& Research, vol. 35, no. 4, pp. 379-386, 2017.

[32] Y. Li, L. Xu, and D. Li, "Examining relationships between the return policy, product quality, and pricing strategy in online direct selling," International Journal of Production Economics, vol. 144, no. 2, pp. 451-460, 2013.

[33] K. Lao, "Research on mechanism of consumer innovativeness influencing green consumption behavior," Nankai Business Review International, vol. 5, no. 2, pp. 211-224, 2014.

[34] H. Tian and H. Yuan, "The contingent effect of corporate social responsibility fit on consumer brand attitude: A research on boundary conditions of consumer attribution," Nankai Business Review International, vol. 4, no. 4, pp. 349-364, 2013. 


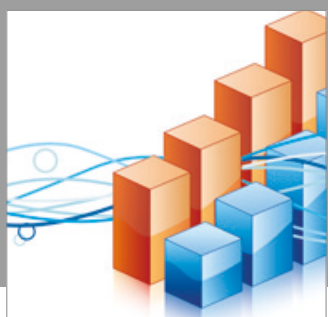

Advances in

Operations Research

vatersals

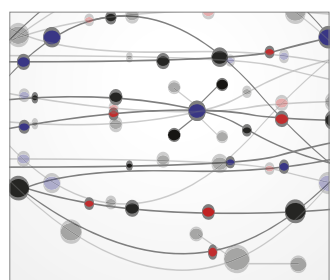

\section{The Scientific} World Journal
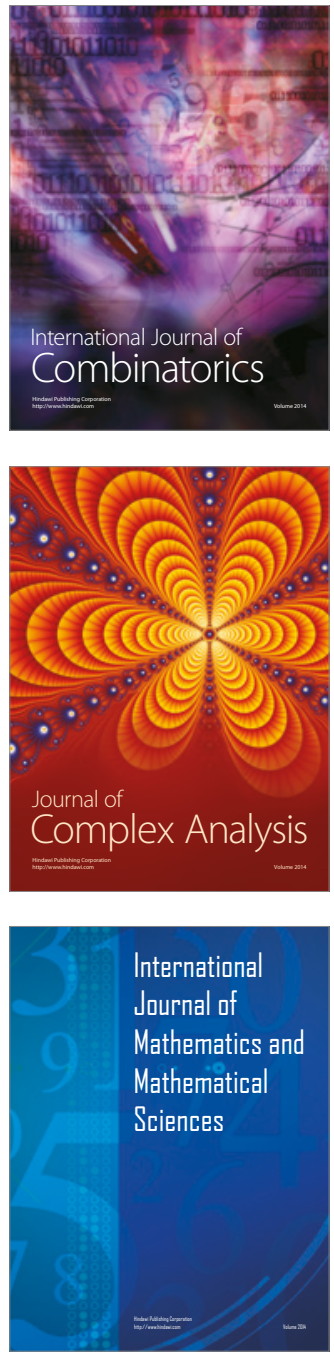
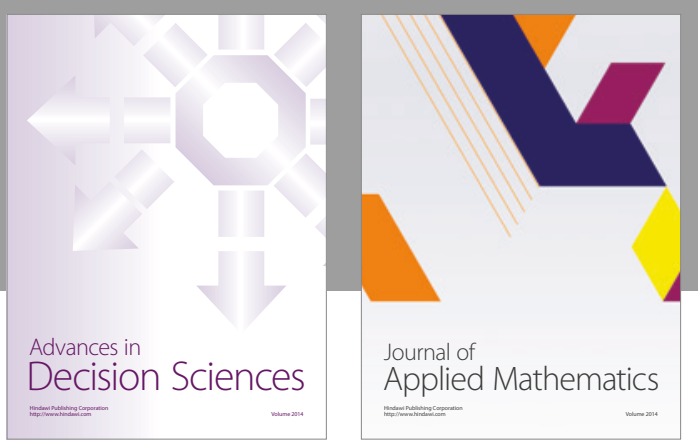

Algebra

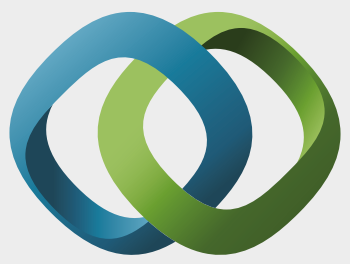

\section{Hindawi}

Submit your manuscripts at

https://www.hindawi.com
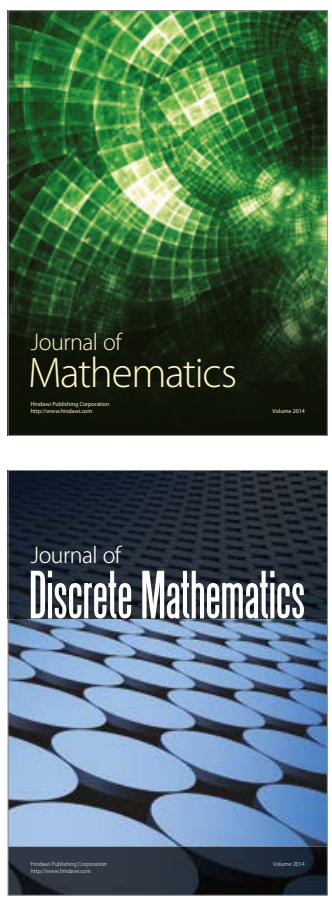

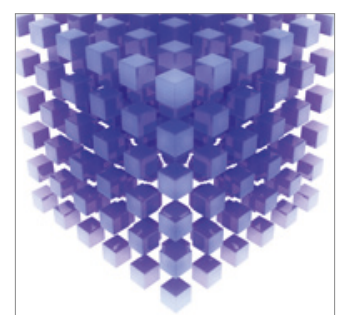

Mathematical Problems in Engineering
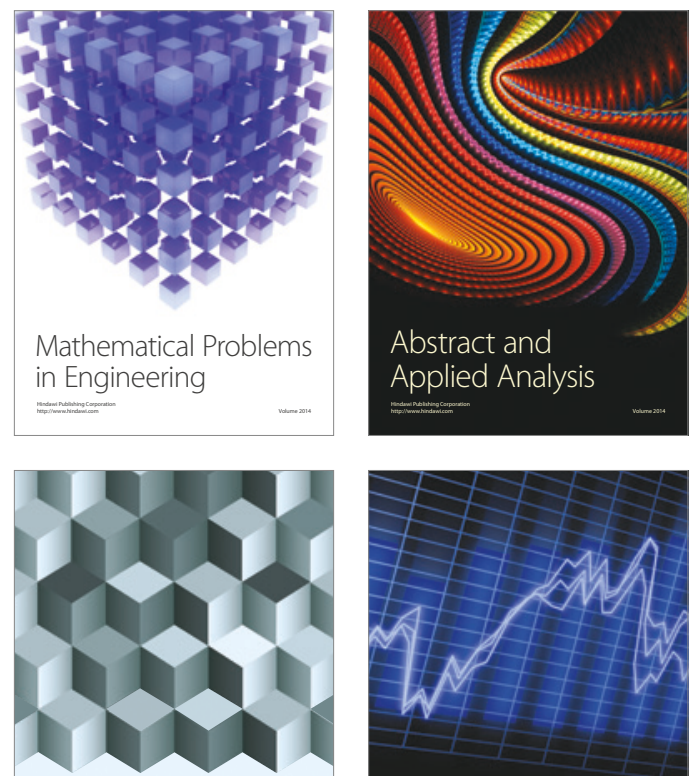

Journal of

Function Spaces

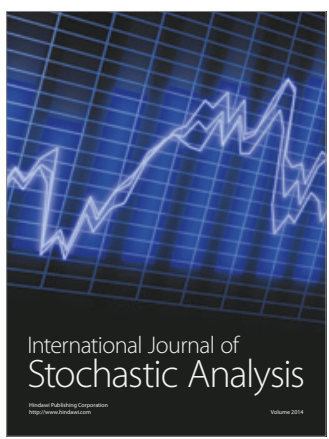

Probability and Statistics
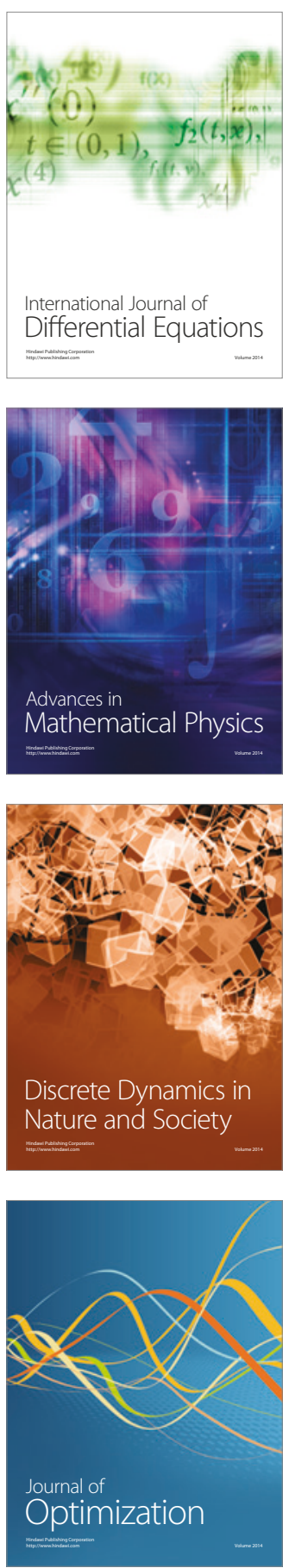